\title{
RECENT ENTOMOLOGICAL LITERATURE
}

American Insects, BY VERNON L. KELLOGG, PROFESSOR OF ENTOMOLOGY AND LECTURER ON BIONOMICS IN LELAND STANFORD JR, UNIVERSITY, WITH MANY ORIGINAL ILLUSTRATIONS BY MARY WELLMAN. HENRY HOLT \& COMPANY 1905. 674 pages, 8 r 2 figures and $\mathrm{I}_{3}$ colored plates.

This work easily ranks as the most comprehensive volume treating of American insects yet produced. The great progress in entomology during the decade which has elapsed since the appearance of Comstock's Manual, has enabled the author to give more adequate treatment to the dragon flies, to the previously almost unknown Culicidae and to the part taken by insects in the transmission of diseases. This latter, comprising an entire chapter, is a new and exceedingly important addition to a comprehensive work on American insects. There is a general systematic account of all the principal groups with special discussions of insect structure, physiology, development, metamorphosis and ecology, portions of which have been greatly enriched by the author's personal investigations. The systematic part agrees largely with Comstock except that the Coleopteras Diptera and Lepidoptera are treated in the order named. The synoptic key, have been summarized in certain groups and in others there are valuable additions, particularly in the Odonata and Orthoptera. The treatment of the Coleoptera, considering the importance and popularity of the group, appears rather brief in comparison with the space usually accorded this order in other works. Considerable attention is devoted to the economic aspects of the subject and a decided preference for the more injurious forms is exhibited in discussing typical species of the various groups considered. A very large majority of our more destructive insects are noticed, with a summarized statement of the life history and directions for controlling these pests. The interesting problems presented by social communities such as white ants, true ants and bees receive considerable attention. The important relationship existing between insects and flowers, the value of color and pattern and their uses, are discussed somewhat fully in two philosophic and very suggestive chapters. The work closes with an appendix on collecting and rearing insects.

The subject matter is presented in an easy narrative style, though accuracy is not sacrificed for the sake of popularity. The work itself is plainly printed on excellent paper and the illustrations are generally of a high standard. 'The volume exhibits a thorough appreciation of and familiarity with recent investigations and, considering the immense field covered, it is not surprising that there 

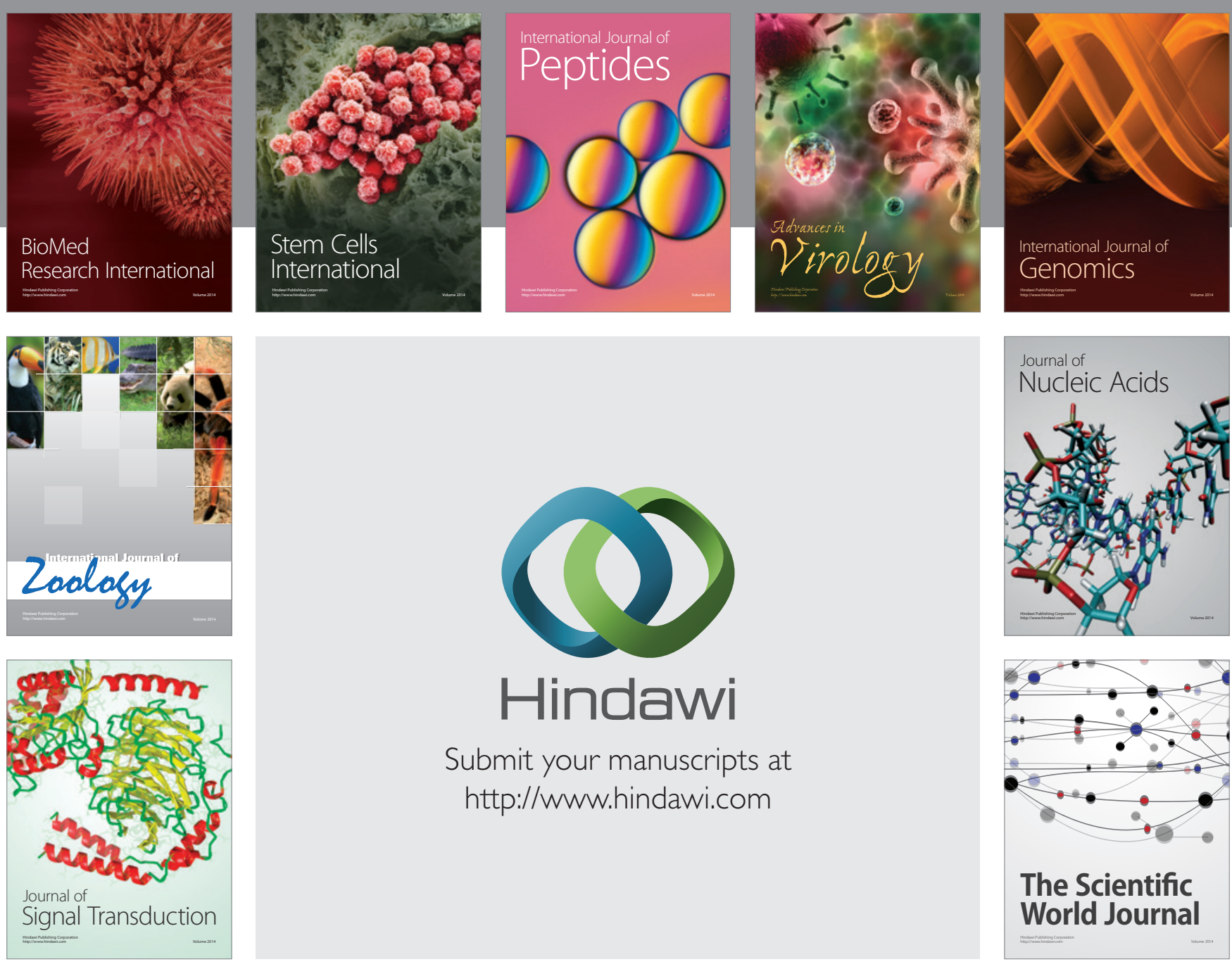

Submit your manuscripts at

http://www.hindawi.com
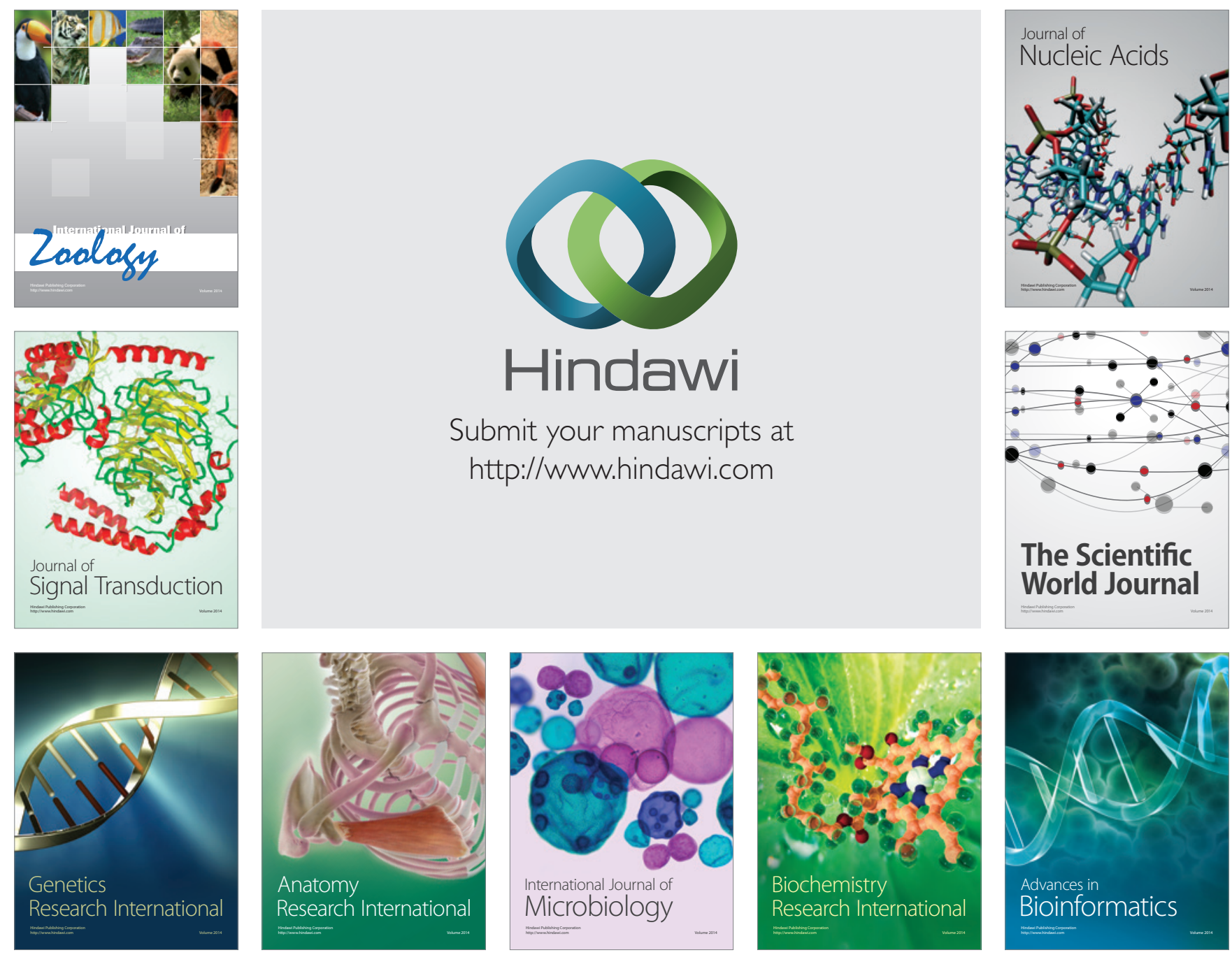

The Scientific World Journal
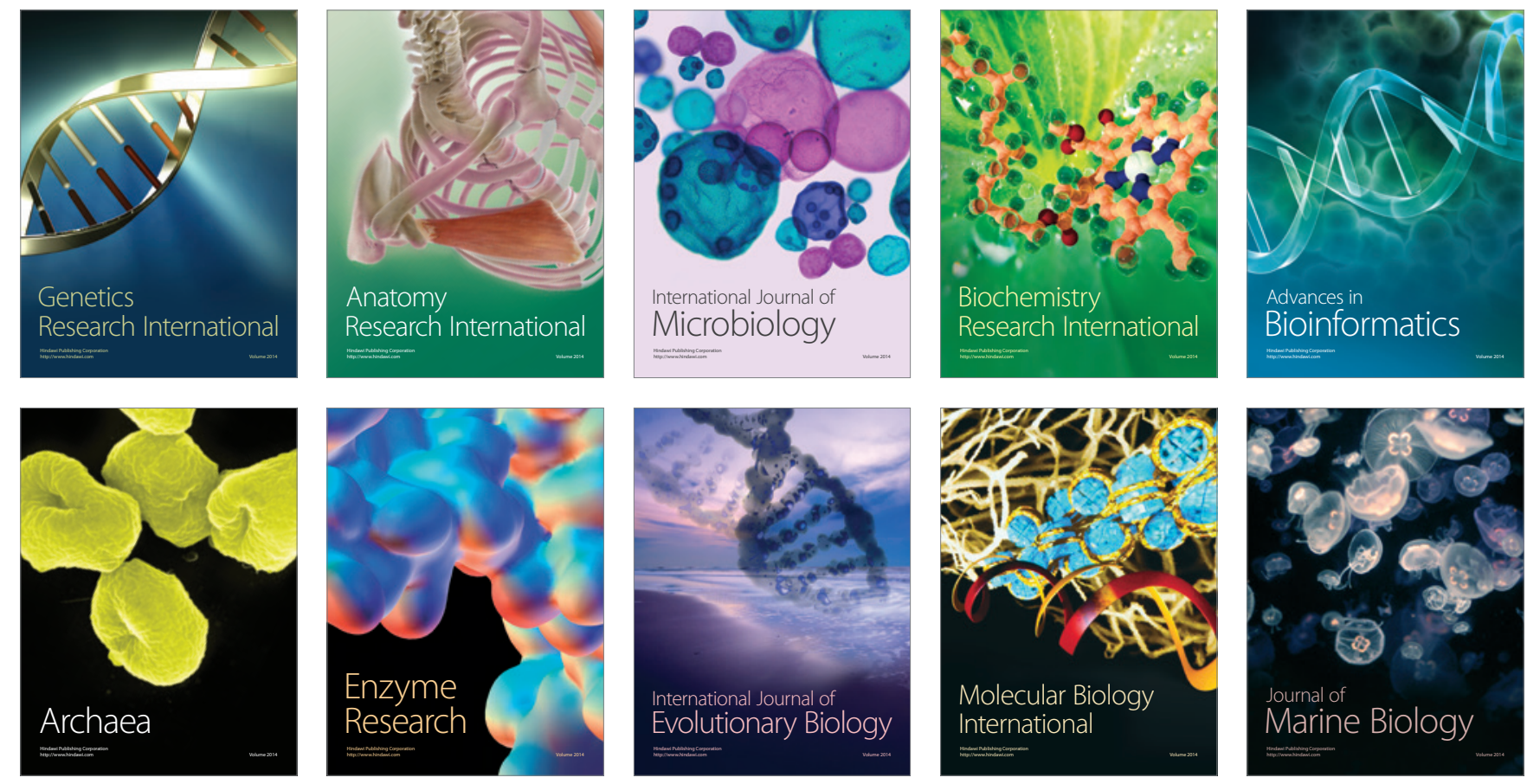